\title{
LA BARCA DE PIEDRA DE SAN JUAN DE LA MISARELA: CARACTERÍSTICAS, PARALELOS Y ORIGEN DE UNA EMBARCACIÓN LEGENDARIA
}

\author{
por \\ FERNANDO ALONSO ROMERO \\ "A la orilla del río se ve una piedra que \\ llaman el Barco, y dicen que en él vino \\ San Juan..." (Sarmiento, Mr.Fr., 1745)
}

Nosa Señora da Barca, en Muxía (La Coruña), no fue la única que navegó por las costas gallegas en un barco de piedra, también san Andrés de Teixido (La Coruña) y el Apóstol Santiago utilizaron estas extrañas embarcaciones para llegar hasta Galicia.

La asimilación de la religión católica dio lugar en Galicia a una religiosidad popular característica, en cuyas manifestaciones perviven creencias paganas, procedentes no sólo del mundo romano, sino también de la cosmovisión céltica del área atlántica. A ella hay que atribuir los cultos a los santos que navegaban en barcos de piedra: una de las muchas muestras de la religiosidad popular gallega, que convirtió una imagen mitológica: la barca, en un símbolo de la nueva fe.

La Galicia romana fue ocupada por los suevos desde principios del siglo V y a lo largo del VI. Parece ser que aceptaron el sistema administrativo romano, pero desde el punto de vista religioso eran arrianos. Sin embargo, un siglo después, bajo la influencia de San Martín de Braga, se 
hicieron católicos. "Y a partir de su conversión se reúnen varios concilios en la capital del reino, es decir, Braga, los años 561 y 572, que se conocen como Bracarense I y Bracarense II. En el segundo de estos concilios aparece el nombre de la iglesia de cada obispo firmante, detalle que se echa de menos en el primero. En este contexto aparece la mención del obispo Mailoc, prelado de la Britonensis ecclesia. Es el único de los nombres de obispos de esta sede que es céltico, y significa grande" (García y García, 1986, 124). "Es evidente que el obispo Mailoc, precristiano en su aristocrático nombre, debió ser el jefe que acaudilló a un grupo de britones en su aventura migratoria. La adaptación de los inmigrantes al país y la pérdida de su personalidad nacional y lingüística en un ambiente geográfico y étnico no demasiado distinto al de su país de origen, hubo de ser bastante rápida, a juzgar por los nombres ya no bretones de los representantes de la diócesis en los concilios del siglo VII" (Tovar, A., 1972, 157). La sede de la Britonensis ecclesia estaba en la actual Santa María de Bretona (Lugo), a 15 kilómetros de San Martín de Mondoñedo. En las últimas excavaciones realizadas en Bretoña se descubrió que los bretones habían construido sus asentamientos sobre un antiguo castro de doble foso, en el que aparecen diferentes objetos de época pre-romana. También se encontraron vestigios de la iglesia bretona y dependencias de la probable comunidad monacal (Chamoso Lamas, 1975).

En el siglo VII las relaciones culturales entre la iglesia irlandesa y la hispana habían sido muy importantes, sobre todo debido a la obra de San Isidoro. Según J.N. Hillgarth, especialista en este tema, los monjes irlandeses del siglo VII estaban muy familiarizados con las obras de San Isidoro, que habían llegado a Irlanda directamente desde la Península Ibérica, y que después influyeron en Beda y en otros escritores anglosajones de ese siglo (Hillgarth, J.N., 1984). Monjes irlandeses que navegaban en sus barcos de cuero directamente desde Irlanda, o quizá más probablemente con escalas en Cornualles y en la Bretaña, se mantenían en contacto con la Península Ibérica y es muy posible que hubieran participado en los asentamientos bretones en el norte de la Península. Debemos tener en cuenta que en esa época los monjes irlandeses navegaban en curraghs, ligeras embarcaciones de cuero que estaban muy condicionadas por los vientos y las corrientes. Para efectuar la singladura desde Irlanda al Continente europeo necesitaban vientos de componente norte o noroeste; no es de extrañar, por consiguiente, que muchos curraghs se perdieran en el Atlántico y llegaran impulsados por esos vientos hasta las costas del norte de España. El primer texto donde se hace mención de los asentamientos bretones en el norte de Galicia es un documento firmado en el Concilio de Lugo del año 569, en el tiempo de los suevos (Bernier, G., 1983, 69), en el cual se dice que "a la sede de los britones (pertenecen) las iglesias que

"CUADERNOS DE ESTUDIOS GALLEGOS", Tomo XXXIX, Fascículo 104, Santiago 1991. 


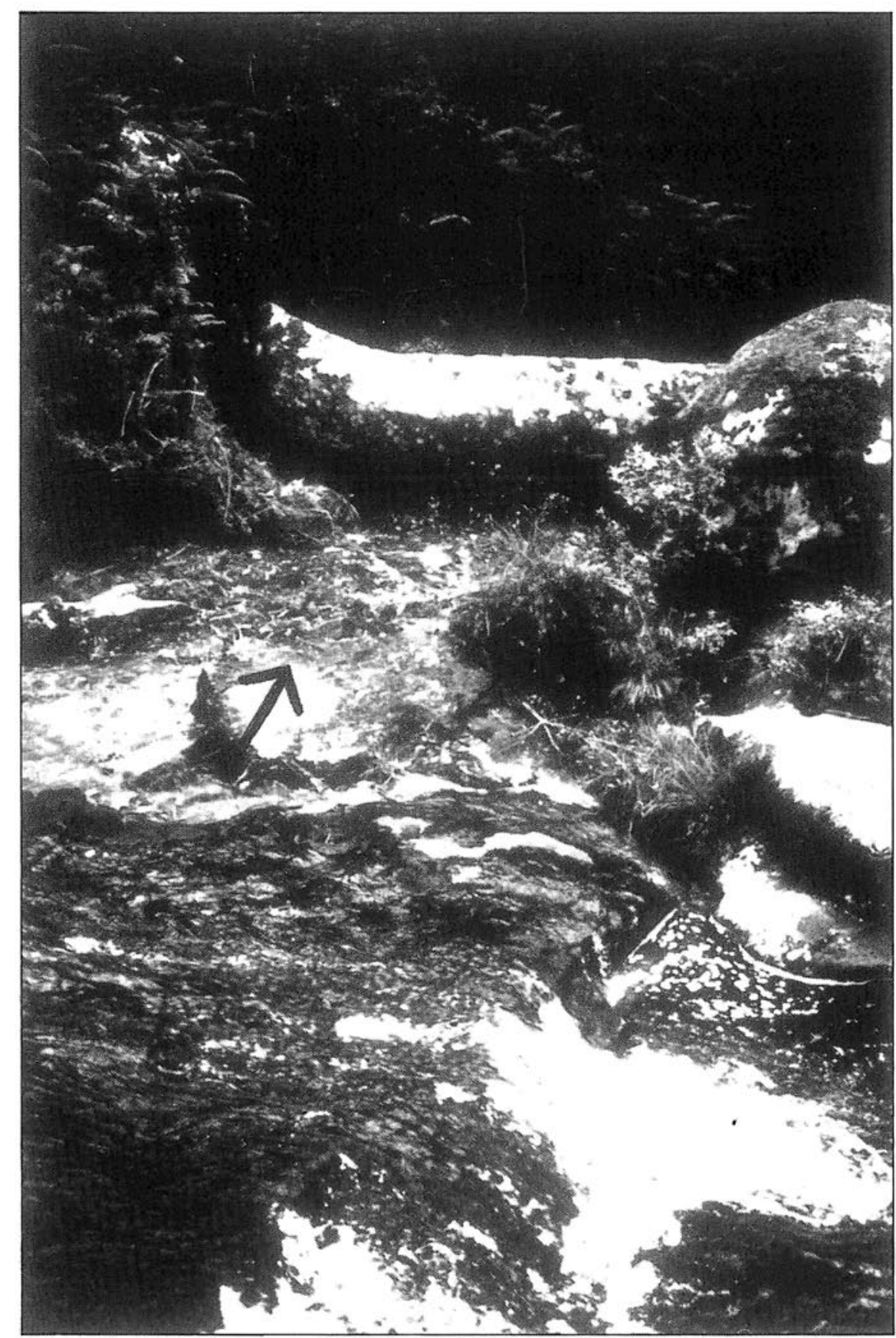

Fig. 1: Fotografía del aspecto actual que ofrece la barca de piedra de San Juan de Misarela. "A la orilla del río se ve una piedra que llaman el Barco, y dicen que en él vino San Juan y otras pataratas semejantes" (Fr. Martín Sarmiento, 1745) 
hay entre los britones, junto con el monasterio de Máximo, y las que están en Asturias" (David, P., 1947, 44. Cf. García y García, A., 1986. 121).

El Monasterium Maximi parece ser que estaba en San Martín de Mondoñedo, a juzgar por la importancia de los restos arqueológicos que se descubrieron en San Martín y que coinciden con la época del concilio (Chamoso Lamas, M., 1967, 359). Según Bernier, las comunidades bretonas establecidas en Galicia, y que mantenían comunicaciones marítimas con sus sedes en Armórica y en las Islas Británicas, "desaparecieron a raíz de las incursiones musulmanas en el año 716 . La restauración, obra ya del clero visigodo, no permitió ya nunca más el mantenimiento de la originalidad bretona. Por otro lado, desde el siglo VII se nota ya en Britonia (Lugo) la presencia de obispos titulares que ya no llevan nombres bretones" (Bernier, 1983, 74). Pero sus obispos "asisten regularmente a los concilios en el siglo VII, y suscriben sus actas con los demás obispos en nombre de su sede Britoniensis. De las demás fuentes transcritas parece deducirse también que había en algunas partes de Galicia, a lo largo del siglo VII, peculiaridades de origen céltico. Otro detalle que emerge de estas fuentes y que conviene no olvidar, es que en el siglo VI se habla de sedes Britonorum, mientras que en el VII aparece la variante Britaniensis ecclesia" (García y García, A., 1986, 126). Un texto de Orosio nos permite pensar en la posibilidad de que los monjes irlandeses hubieran llegado a Galicia a comienzos del siglo $\mathrm{V}$, puesto que Orosio menciona que en España había un gran faro en una ciudad llamada Brigantia que era visible desde el río Scena (el Shannon) en el suroeste de Irlanda (Orosio, I, 2.71, 80, 81. Trad. Torres Rodríguez, 1985). Rolf Baumgarten (1984, 201) se pregunta si el interés de Orosio por Irlanda era debido a la influencia del comercio que este país mantenía con el noroeste de la Península Ibérica. Un anónimo irlandés del siglo VII, que estudió el Profesor Díaz y Díaz (1972), refleja la importancia que debieron de tener las comunicaciones marítimas de Irlanda con el Continente europeo, fundamentadas en una larga experiencia que venía ya desde la Prehistoria (Alonso Romero, 1976). El anónimo autor de ese manuscrito tenía que estar muy al corriente del comercio irlandés cuando expresó su visión de las relaciones marítimas en los siguientes términos: "A menudo delimitan los espacios terrestres las aguas del mar, que así enmarcan los territorios de las naciones y enriquecen con la munificencia de sus frutos todas las provincias de los diversos pueblos: más aún, extendiéndose entre los diversos países facilitan mutuamente las convenientes relaciones comerciales" (Díaz y Díaz, M., 1972, 149).

Muchos de los santos evangelizadores que aparecen en las leyendas irlandesas, bretonas y gallegas, se presentan en el mundo de los vivos de 


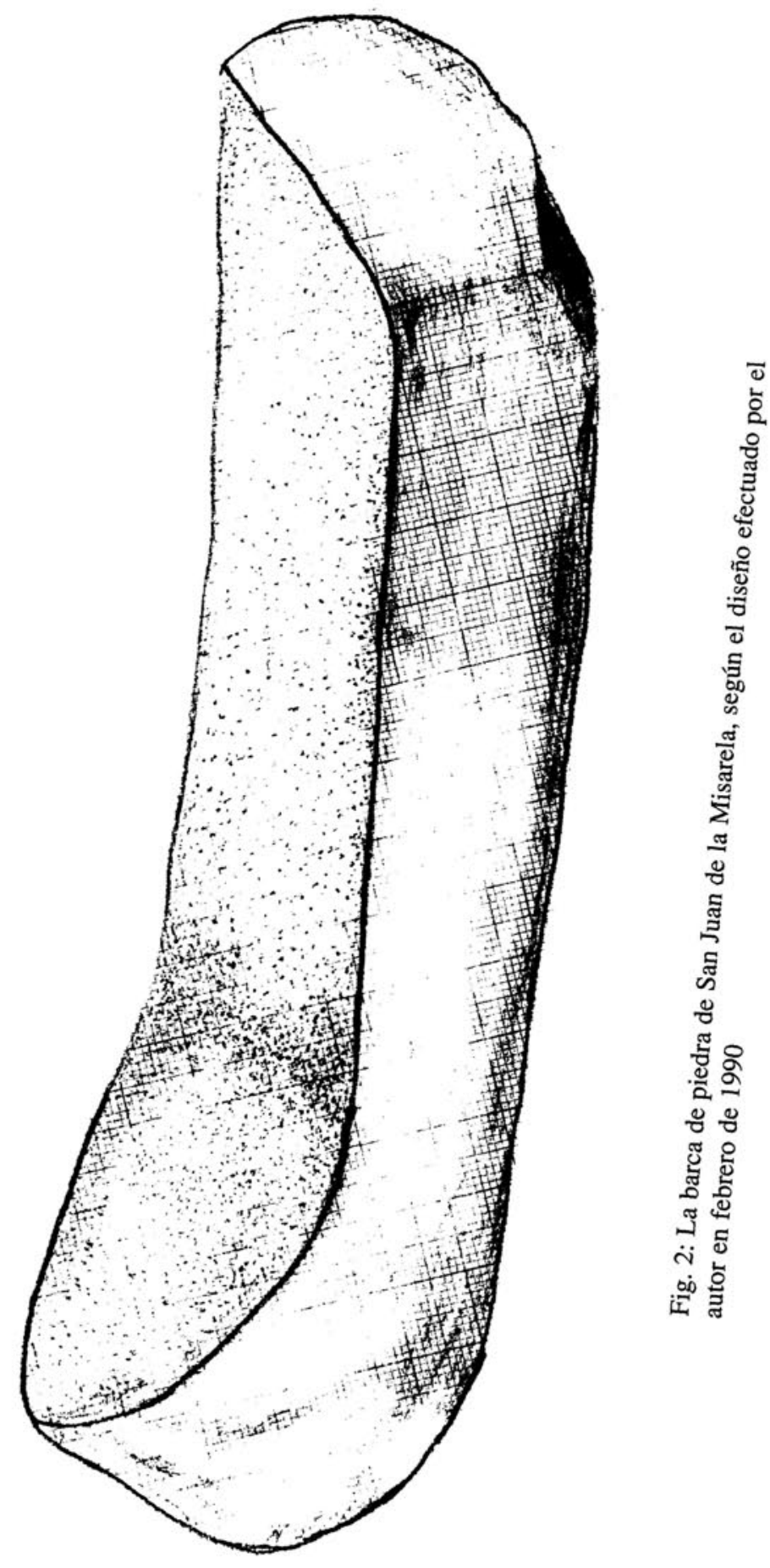


una forma sorprendente: navegando sobre las olas del mar en barcos de piedra. En algunos casos se cita su procedencia, en otros se dice simplemente que venían por el mar, procedentes de un Más Allá que la mentalidad del creyente relaciona con el Paraíso, o con el mundo particular de su fantasía en el que supone que moran los seres divinos. Se cree tradicionalmente que san Boec llegó navegando hasta Bretaña sobre una piedra que lo trasladó a Penmarch, en la parroquia de Treguenec. Después, dicha piedra volvió milagrosamente a Irlanda, y actualmente se encuentra en la orilla del mar, muy cerca de la iglesia de san Boec en Carnsore Point (parroquia de Carn.Wexford). Aunque un trozo de dicha barca se quedó en la Bretaña en el cementerio de la iglesia de san Boec, en Penmarch. Dicen que en ella quedó grabada la cabeza del santo, lo cual despierta gran devoción y se cree que su contacto produce alivio a los que padecen de fiebres (Logan, P., 1980, 103).

San Piran, que predicó en Irlanda, fue condenado a muerte por unos nobles irlandeses. Para cumplir la sentencia, lo lanzaron al mar desde un acantilado con un apiedra de molino atada al cuello. Pero cuando ésta tocó las aguas del océano, empezó a flotar igual que una embarcación, llevando sobre ella al santo; y de ese modo llegó san Pirán a las costas de Cornualles (Hunt, R., 1969, 18). Prudencio, poeta cristiano nacido en Calahorra y coetáneo de Prisciliano (Ortega, A., 1981, 62), nos narra un milagro parecido. Relata que san Quirino de Yugoslavia, martirizado en el año 308, fue arrojado a un río atado a una rueda de molino, pero ésta navegó milagrosamente sobre las aguas con el cuerpo del santo encima (Himno VII. Ortega, A., (Trad.), 1981, 23). Prudencio después de su viaje a Roma se había convertido en un decidido propagador del culto a los santos por medio de la exaltación de los mártires en sus himnos, que servían para intensificar la necesidad de tener presente el mundo heroico de los mártires (González Blanco, G., 1981, 198). Es en Prudencio también donde encontramos la narración de otro milagro que pudo inspirar - digo esto con reservas - a los autores de algunas de las leyendas de los santos irlandeses. Uno de los santos más populares en España fue el diácono Vicente de Zaragoza, martirizado por el prefecto Daciano en Valencia. Después de sufrir terribles tormentos, Daciano ordenó que el cuerpo del diácono fuera arrojado al mar atado a una pesada roca, la cual, ante el asombro de todos, flota como una barca llevando al cuerpo del santo hasta la orilla (Ortega, A., (Trad.), 1981, 587):

Saxum molaris ponderis La piedra, pesada como muela, 490 ut spuma candens innatat, cual blanca espuma sobrenada, tantique custos pigneris y la esportilla que tal tesoro guarda fiscella fertur fluctibus navega por encima de las aguas. 
Cernunt stupentes nauitae uectam remenso marmore

495 labi retrorsum leniter aestu secundo et flamine

505 Felix amoeni litoris secessus ille, qui sacra fouens harenis uiscera uicem sepulcri praebuit,

dum cura sanctorum pia

510 deflens adornat aggerem tumuloque corpus creditum uitae reseruat posterae!
Así llevada por la mar, en calma recorrida, la ven los asombrados marineros hacia la playa deslizarse con vientos y marea favorables

¡Feliz la cala aquella del litoral ameno que, abrigando el cuerpo santo en sus arenas, prestóle oficio de sepulcro

hasta que la piadosa diligencia de los santos arregla, entre lágrimas, un cerro, y el cuerpo confiado a este sepulcro guarda para la vida venidera!

Estos versos son de enorme interés para nuestro estudio, pues pudieron servir de modelo a los cristianos que imaginaron la navegación del cuerpo de Santiago Apóstol en una barca de piedra hasta las orillas de $\mathrm{Pa}$ drón. Prudencio vivió varios siglos antes del descubrimiento del sepulcro del Apóstol en Santiago de Compostela, por lo tanto, su obra se conocía perfectamente a comienzos del siglo IX, fecha del descubrimiento y en torno a la cual se dio gran difusión a la leyenda de la barca de piedra atribuída a Santiago. Pero esta suposición la menciono con muchas dudas, ya que también parece existir en esa leyenda un transfondo precristiano que aún no ha sido aclarado debidamente; pues, ¿cómo explicaríamos las leyendas en las que los santos navegan en barcos de piedra o en piedras que no han tenido ninguna relación con sus vidas o sus martirios? Por ejemplo, en el País de Gales también se habla de santos que vinieron desde Irlanda o desde la Bretaña en piedras que navegaban sobre el mar (Gwyn Jones, T., 1979, 94. Cf. Brewer, 1853, 6, 191). Y san Feock se alejó de las costas de Irlanda navegando sobre una roca de granito (I.G.B., 1974, 63). En la playa de Ardmore (Co. Waterfod. Irlanda) hay un laja de grandes proporciones sobre la cual se dice que san Declan llegó navegando hasta Irlanda. El 24 de julio, festividad del santo, es costumbre pasar arrastrándose bajo la laja como remedio para las enfermedades de la espalda (Logan, P., 1980, 80). La misma práctica de curación existe en la parroquia de Santa María de Muxía (La Coruña), donde la tradición popular nos habla de que cuando Santiago se encontraba predicando por esas latitudes, se retiró un día a orar a la orilla del mar. Cuando estaba sumido en sus meditaciones vio una misteriosa barca que se acercaba a 
la orilla y en ella venía la Virgen, "radiante de hermosura y majestad. La Virgen alienta al Apóstol, comunicándole el éxito de sus predicaciones en nuestra tierra, ordenándole el regreso a Jerusalén en donde le espera el martirio y dándole como muestra de amor una imagen suya, a quien Santiago erigió un Altar en una cueva, formada bajo las rocas" (Rivadulla Porta, J.E., 1974, 9). Recordemos que la embarcación en la que había llegado la Virgen hasta Muxía era de piedra, al igual que la vela y el timón. La fiesta de la Virgen de la Barca es una de las más famosas de Galicia, y se celebra entre el 7 y el 10 de septiembre. El día 8 de ese mismo mes, romeros de todas partes de Galicia acuden a San Andrés de Teixido para visitar a este santo tan vinculado en el folklore gallego con la vida en el Más Allá (Usero, R., 1972). La leyenda dice también que San Andrés llegó a Teixido en una barca de piedra, que ahora es una roca de Punta Gaveira, conocida precisamente con el nombre de barca de San Andrés.

"Oh divino San Andrés,

velo, ahí ven na sua barca;

aló, no medio do mar

toda-las augas aparta" (Maciñeira, F., 1921, 91).

En la iglesia de Kilbarry (Roscommon. Irlanda) se guarda una piedra que tiene cierto aspecto de embarcación. Los fieles dicen que fue el bote que utilizó san Barry para cruzar el río Shannon (Logan, P., 1980, 104), desde donde decía Orosio que se veía el faro de Brigantia.

El Padre Sarmiento durante su viaje por Galicia en 1745, recogió otra creencia relacionada con los barcos de piedra: "A la tarde salimos a ver la Misarela. Es uno de los sitios más solos, y lóbregos, fuimos por la Ponte da Croche, rio das Pedras, Santa Cruz de Lesón y la Misarela, el que está en la feligresía de San Isidro de Postomarcos en Laraya, al oriente del rio que se despeña y su cascata parece mejor de lejos".

"San Juan de la Misarela, es uno de los sitios más lóbregos, solos, escarpados y estrechos que se puede imaginar para ermitaños. Ha sido monasterio o eremitorio de benedictinos. Después se dio a los franciscanos, pero no pudiendo subsistir allí, se fueron a fundar a la Puebla del Deán, o a su cercanía".

"En lo más alto de las montañas, a las orientales vertientes del monte de la Curota, se despeñan, dos riachuelos. El del oriente se llama de Barbanza; el del poniente el Folgoso o el Rio das Bestas, los cuales unidos después componen el Rio das Pedras, que dije arriba; pero el Folgoso es el que más se despeña y se ve como rio de espuma desde lejos".

"Estos (dos) rios distan poco entre sí en lo alto, y después se unen y en el interamnium están las ruinas del conventico, cuyo territorio apenas bastó para el edificio. Ví las ruinas, y se ve aún la iglesita, y la corta habi-

"CUADERNOS DE ESTUDIOS GALLEGOS", Tomo XXXIX, Fascículo 104, Santiago 1991. 


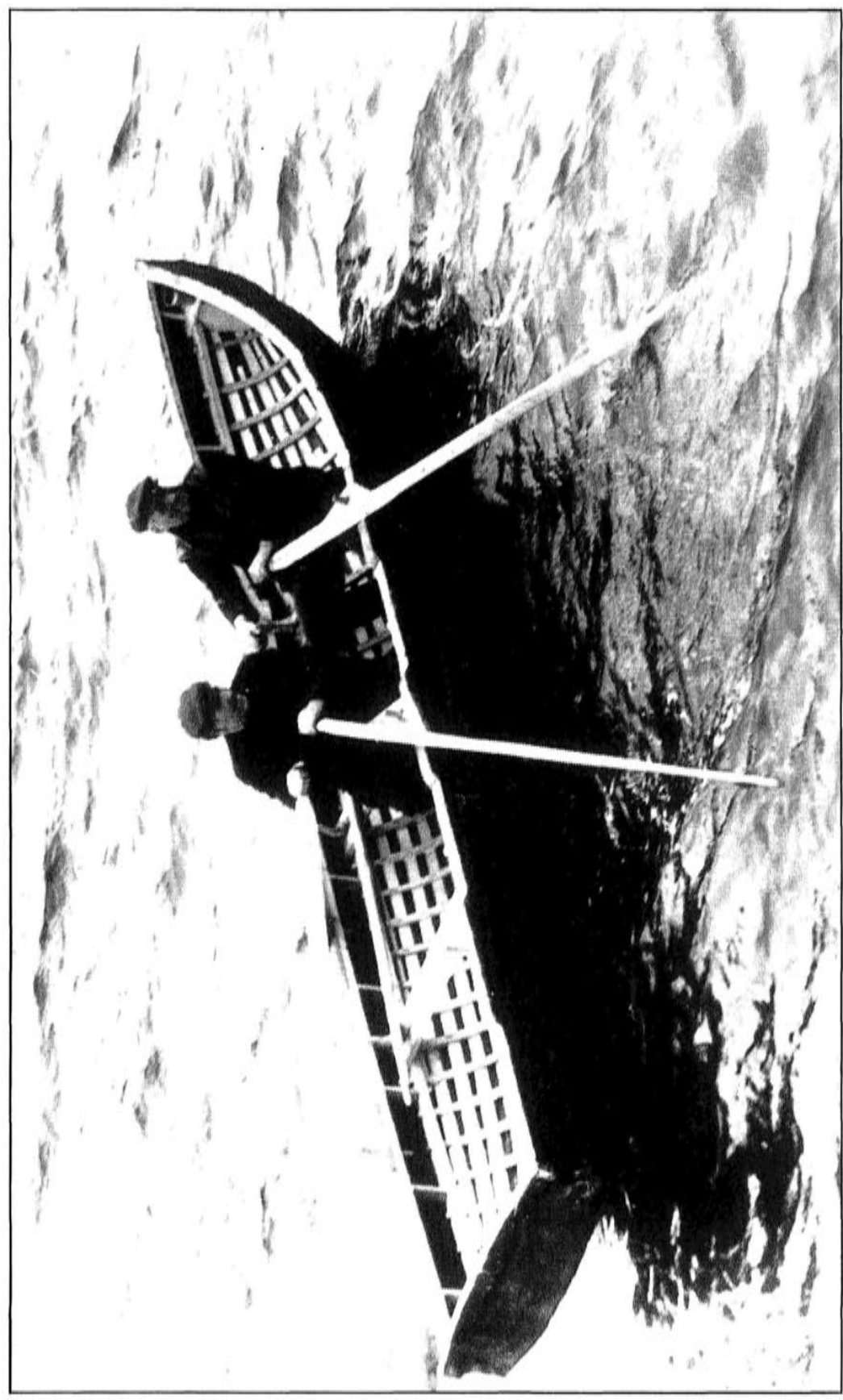

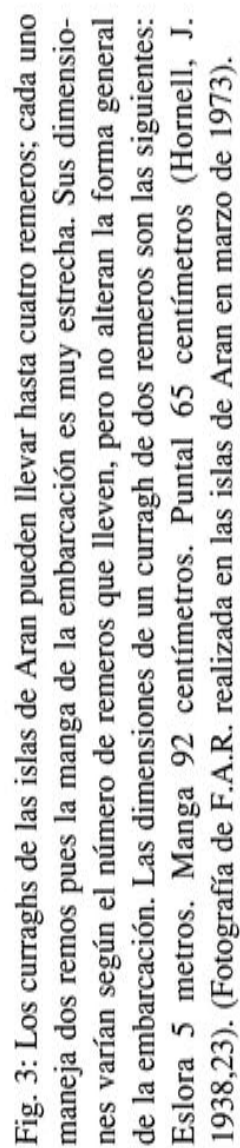


tación pero todo yermo. Y apenas se puede tener uno en pie en aquel paraje, tanta es la cortedad del terreno que admira como allí podían vivir racionales".

"Del rio Barbanza, que es mayor que el Folgoso, cuentan mil cosas, v.g.: que había allí un pozo sin fondo, en que se veían encantadores, etc., y que con truenos se cegó del todo. A la orilla del rio se ve una piedra que llaman el Barco, y dicen que en el vino San Juan y otras pataratas semejantes" (Fr. Martín Sarmiento. Ed. J.L. Pensado, 1975, 88).

Esa piedra de la que habla el Padre Sarmiento se encuentra efectivamente en el cauce del río Barbanza a unos cien metros de su confluencia con el río das Pedras (Fig. 1). Frente a ella y al otro lado del río se levantaba el eremitorio de San Juan de la Misarela (Laredo Verdejo, L., 1981, 51) (Fig. 5). No se ha efectuado todavía un estudio arqueológico de los restos que se ven esparcidos por la zona, por lo que ignoramos a qué época se puede remontar su origen, aunque debe ser muy antiguo por la referencia que hace el Padre Sarmiento a los benedictinos y por la leyenda de la barca de piedra, que varada todavía a la orilla del río reveló tras un estudio detenido de sus proporciones una sorprendente información (1). En la actualidad continua vigente la leyenda que recogió el Padre Sarmiento, aunque la tradición oral dice que el eremitorio lo fundó San Mauro, que llegó hasta allí en un barco de piedra, "los moros - dicen algunos vecinos - le perseguían, pero la providencia, según iba el santo remontando el río, lo iba llenando de cantos rodados para obstaculizar el paso de sus perseguidores", de ahí el nombre de río das Pedras (Erolo, 1984,31 ). Esta leyenda del santo, que al huir va lanzando hacia atrás piedras que se transforman en grandes bloques para obstaculizar la persecución, relata una práctica cuya distribución geográfica en los cuentos populares sobre huidas mágicas es casi universal (Von Sydow, C.W., 1965, 233. Cf. Propp. V., 1981, 506). Un relato parecido en el que la providencia también acude en ayuda de un santo que navega en barco de piedra, lo encontramos en la leyenda irlandesa de san Buadan, que en cierta ocasión en la que se veía acosado por sus enemigos escoceses, llegó huyendo hasta la orilla del mar; allí se subió a una roca que milagrosamente se separó de la costa y llevó a san Buadán sobre las aguas del mar hasta Culdaff (Península de Inishowen) en Irlanda (Logan, P., 1980, 105).

Son frecuentes las leyendas bretonas que nos describen la llegada a Bretaña de los primeros monjes celtas que venían en barcos de piedra desde las Islas Británicas. De ellas procedía el patrón de la parroquia de Plonéour-Lavern (Quimper. Bretaña), san Enéour, pero de su embarcación, dicen los feligreses, solamente se conserva el mástil de piedra; así es como denominan al menhir prehistórico que se encuentra delante de la 
iglesia (Gwenc'hlan, L.S., 1979, 495). En el siglo VI llegó a la Bretaña un santo irlandés llamado Ronan, que venía huyendo de los anglosajones. Según la tradición vino en un barco de piedra, que los bretones dicen que es una roca denominada Kador sant Ronan, en donde suelen sentarse las mujeres estériles por considerar que tiene poderes fertilizantes. Esta roca se encuentra en las cercanías de Locronan (Douarnenez), donde precisamente se celebra una de las romerías más relacionadas con el Otro Mundo, en muchos aspectos comparable a la de San Andrés de Teixido. En nombre de San Román se celebra cada seis años en Locronan una romería que recorre doce kilómetros. La tradición dice que "el que no hace esta romería de vivo, la hará de muerto y no avanzará cada días más que la longitud de su ataud" (An hini ne raerae ket an Droveni e bew, he raio marw a hed e cherj bemdeiz) (Gwenc 'hlan, L.S., 1979, 375). Su fiesta se celebra en ese finisterre bretón' el segundo domingo de julio.

En Beuzec-Cap-Sizum (Bretaña) hay una roca que tiene forma de embarcación. La gente dice que es el navío sobre el que vino san Conogan por el mar. Muy cerca de la capilla de san Vio, en Tréguennec, hay también otra roca con forma de barco sobre la cual los fieles creen que vino san Vio desde Irlanda. Al desembarcar el santo, la piedra se partió en dos fragmentos; uno se quedó en la orilla y el otro volvio a Irlanda (Sébillot, P., 1983, B, 145). También cuentan que san Gerbold cruzó milagrosamente las aguas de la costa de Bessin (Bretaña) sobre la rueda de un molino a la que había sido amarrado (Sébillot, P., 1983, A 43).

Antes de concluir esta breve mención de leyendas relacionadas con los barcos de piedra, veamos algunos datos más para reforzar la opinión que expondré al final de este estudio.

San Mogue nació en una isla irlandesa del lago Templeport (en Cavan). Según la leyenda, lo llevaron a bautizar a la orilla cercana en una losa de piedra que navegaba sobre el agua. Dicha piedra se quedó en el lugar del bautismo. Como era una piedra santa que podía navegar, se utilizaba par transportar los cadáveres hasta el cementerio que estaba en la isla del lago. Durante mucho tiempo, según relata la leyenda, no ocurrió nada anormal en esas travesías fúnebres, hasta que cierto día una pareja de novios decidió ir a la isla en ese barco de piedra. Ante tamaña ofensa, la piedra se rompió en tres pedazos, y la joven pareja pereció ahogada. Un fragmento de la piedra llegó flotando hasta la isla de san Mogue, otro a un pequeño islote del lago, y el tercero a las orillas del lago, en donde todavía se puede ver en la actualidad pues se conserva en la iglesia de Kildoe convertido en pila de auga bendita (Logan, P., 1980, 103). En Lough Ree (Irlanda) dice la tradición que había también una losa de piedra que se utilizaba como barco para llevar los cadáveres hasta la Isla de los Santos. Una historia semejante sucedía en las orillas del lago Allen, 
desde donde partía un barco de piedra que transportaba a los muertos hasta la isla de Inismagrath (Irlanda) (Logan, P., 1980, 104). Las islas y las grandes piedras situadas en medio de los ríos, cerca de un lago o de una fuente, son citadas con frecuencia en las vidas de los santos y en las crónicas irlandesas, porque existía la creencia de que eran lugares en donde habían nacido los santos, los héroes y los reyes. Esto hizo opinar a Ellen Ettlinger que la configuración de determinadas piedras y su situación junto a una corriente de agua, eran factores muy adecuados para dar a luz y para ese fin fueron probablemente utilizadas en el pasado (Ettlinger, E., 1960, 102). Dice Anne Ross que "en las religiones primitivas o politeístas los conceptos de vida y muerte van unidos y la dualidad de las divinidades ctónicas y de fertilidad atestiguan la preocupación por los dos extremos de la condición humana" (Ross, A., 1968, 39). La muerte era solamente una etapa en la vida; "las almas no perecen sino que pasan después de la muerte de un cuerpo a otro", dice Julio César al hablar de las creencias de los celtas galos (VI, 14). De ahí se deriva la atracción popular de los países célticos hacia determinadas piedras y enterramientos supuestamente dotados de virtudes sobrenaturales. Recordemos aquí las tradiciones gallegas e irlandesas sobre las camas de piedra o camas de santo (Alonso Romero, F., 1983, 253), en las que resulta evidente la relación fecundidad-espíritus de los muertos (Carro Otero. Masa Vázquez, 1981, 246).

Fue en dos lugares de la costa sur de Galicia: en Padrón y en el desaparecido eremitorio de san Juan de la Misarela, donde se localizan dos de las cuatro leyendas "gallegas" de santos relacionados con barcos de piedra. Las otras dos leyendas corresponden a la Virxen da Barca, en Muxía, y a San Andrés de Teixido; ambas en el norte de Galicia. Es muy significativa esta distribución geográfica que demuestra claramente la vinculación marítima de dos zonas muy distantes. En ningún otro lugar de la costa gallega - ni tampoco en Portugal — aparece este tipo de leyendas; lo cual reafirma la suposición de que no son oriundas de Galicia sino de la Bretaña o de Irlanda, y que llegaron a Galicia muy probablemente con los monjes de Santa María de Britonia. Es lógico suponer que unos monjes navegantes, que tuvieron que cruzar el Cantábrico para llegar hasta el Noroeste de España, hubieran navegado también por toda la costa gallega y penetrado en las tranquilas aguas de la rías.

La influencia de los monjes bretones en el cristianismo gallego se produjo muchos años antes del descubrimiento del sepulcro del Apóstol en Compostela. Sin embargo, la leyenda de la predicación de Santiago en España llegó a la Península a fines del siglo VII (Sánchez Albornoz, C., 1981, 381). Pudieron ser monjes de Santa María de Britonia los que llegaron hasta Iria Flavia (Padrón) y difundieron entre la comunidad cristia- 


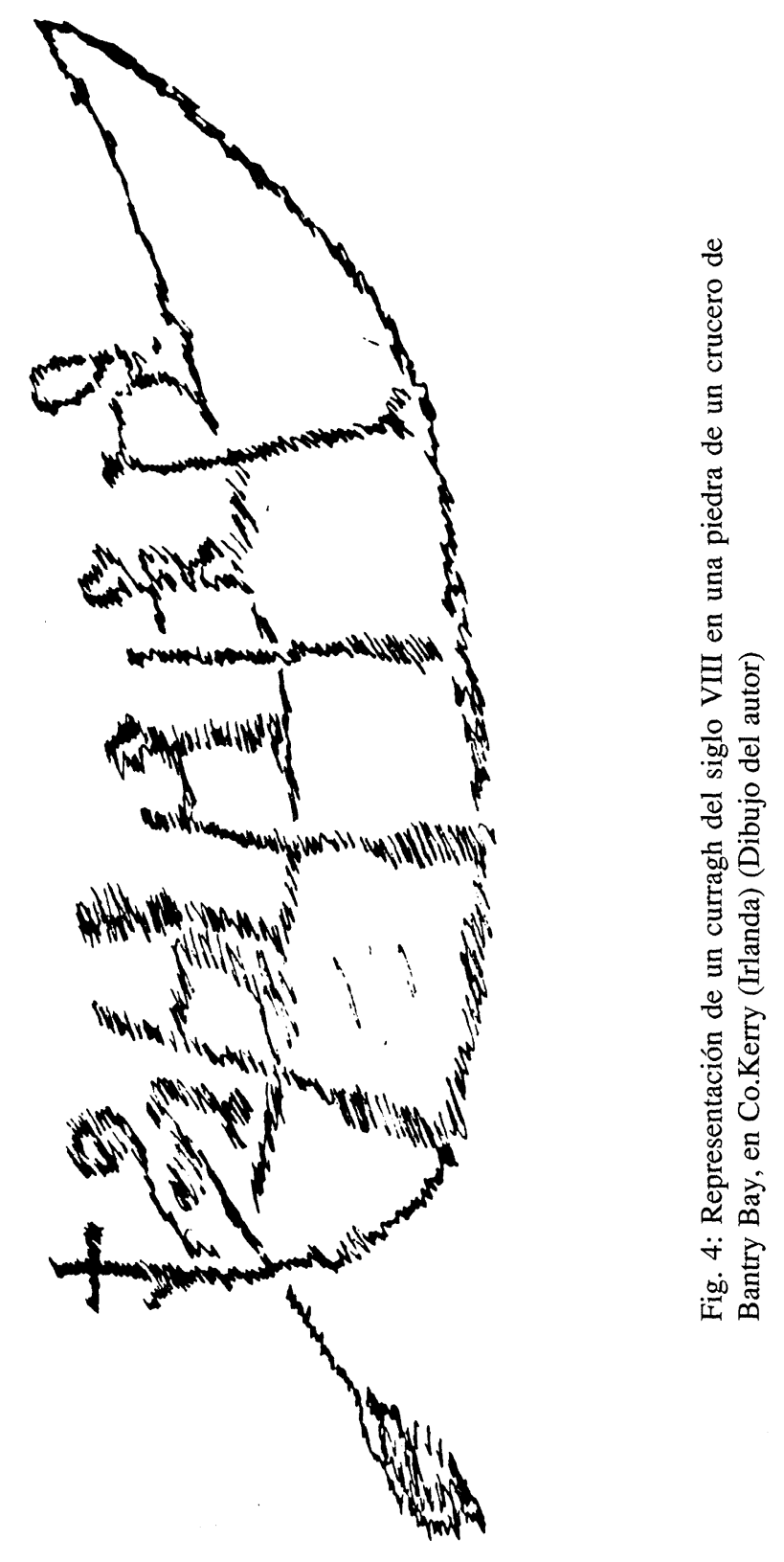


na la creencia de la llegada de Santiago hasta allí en un barco de piedra. Espero poder fundamentar esta suposición en un futuro estudio más detenido con otros datos que no menciono aquí por falta de espacio.

No hay que olvidar tampoco que antes de la llegada de San Martín a Galicia, el panorama monástico estaba también dominado por los priscilianistas, contra los que todavía en el año 561, promulgan los obispos una serie de condenas cuando se reúnen en el Primer Concilio de Braga. En ese Concilio coincidieron el obispo Andrés de la diócesis de Iria y un tal Malioso, que probablemente se trate de una latinización del nombre del obispo de Britonia: Mahiloc (Orlandis, J. y Ramos-Lisson, 1986, 139). Después, en el año 572, se celebró el II Concilio de Braga y en él vuelven a verse el obispo Andrés y el obispo Mahiloc. En esa época la provincia de Gallaecia estaba dividida en dos provincias eclesiásticas: la del norte tenía a Lugo como sede metropolitana, y la del sur a la ciudad de Braga, presidida por el arzobispo Martín, que tanto se preocupó por los problemas que planteaban las herejías en Galicia (Orlandis, et al., 1986, 150), que afectaban no sólo al pueblo llano sino también a los monjes y a los religiosos. En los últimos años del siglo IV un monje llamado Baquiario de Braga, que era adepto al priscilianismo, también estaba en contacto con monjes de la iglesia céltica de las Islas Británicas (Mattoso, J., 1985, 83). Si esto fue realmente así, entonces no sería nada extraño que muchos aspectos del priscilianismo fueran aceptados fácilmente por los primeros monjes celtas. En el año 633 se celebró el IV Sínodo toledano al que también asistieron los obispos de Britonia y de Iria (Sánchez Albornoz, C., 1929, 68), allí el obispo de Britonia reforzó los lazos con la iglesia católica para reducir las discrepancias que había con ella y, sobre todo, para ayudar a borrar las creencias priscilianistas que aún latían en las zonas rurales apartadas. En este Concilio se reprobó expresamente "la tonsura usada por los lectores en Galicia - cabellos largos como los laicos y tan sólo un pequeño círculo en el ápice de la cabeza; esta - dice el Concilio- fue la tonsura de los herejes de España, aludiendo probablemente a los priscilianistas", tema que ya se había tratado en el I Concilio de Braga (Orlandis, J. et al., 1986, 283). Hay que recordar que las diferencias principales entre la iglesia celta y la romana radicaban principalmente en la celebración de la fiesta de Pacua, en el mantenimiento de la figura del abad-obispo, y en la forma de realizar la tonsura, que la efectuaban al igual que los clérigos gallegos censurados en ese Concilio.

\section{La Barca de piedra de San Juan de Misarela}

Un dato más sorprendente, en favor de mi teoría sobre la influencia de los monjes irlandeses y bretones en la difusión de las leyendas de los barcos de piedra, lo aportó el estudio de la, hasta ahora, apenas conocida 
barca de piedra de San Juan de la Misarela. Esta piedra está en la orilla izquierda del río Barbanza, tal y como relata el Padre Sarmiento, frente a la ladera del monte en el que se levantaba el monasterio de la Misarela, a pocos metros de un pequeño puente romano que todavía se mantiene en pie. Con las crecidas del río en invierno, el agua llega casi hasta la barca, que recostada sobre la banda de estribor apunta su proa río arriba, como mudo testimonio de esa fantástica singladura de la que nos habla la leyenda. Si al observarla desde lejos ya se advierte su aspecto de barca, al aproximarnos, el parecido resulta aún más llamativo. Ante ella efectué un dibujo (Fig. 2) de su aspecto general tal y como se ve desde arriba puesto que, al ponerse a su lado, es imposible debido a la diferencia de nivel, abarcar la parte superior, que sólo puede verse subiéndose a la barca o a las piedras de los alrededores. La barca es un largo bloque de granito gris que parece fue desgajado de una roca mayor a la que está arrimado. La parte de babor de la popa se apoya en una roca que probablemente fue arrastrada hasta allí por el agua o por la erosión. La barca mide 4,80 metros de eslora; la regala es totalmente recta, a excepción de su parte de proa, que se levanta marcadamente hacia lo alto para formar el tipo de proa arrufada característica de los curraghs. Este hecho me llamó enormemente la atención desde el principio, ya que es un tipo de proa que no se empleó (ni se emplea) nada más que en los curraghs —o barcos de cuero de los irlandeses-. La semejanza pudiera ser, evidentemente, una pura casualidad; pero lo extraño, lo que no acierto todavía a explicar, es la coincidencia de sus demás proporciones con las de los curraghs de dos remeros de las islas de Aran (costa occidental de Irlanda), que es, además, el tipo de curragh más tradicional, cuyos orígenes son de una enorme antigüedad como ha sido ya demostrado por varios autores (Hornell, J., 1937. McGrail, S., 1987, 186) (Fig. 3). En la Fig. 4 se puede contemplar un diseño de curragh del siglo VIII, de cuatro remeros, por lo tanto mayor que el curragh al que me refiero, pero con las mismas características, pues es un hecho de sobra demostrado, el carácter conservador de las comunidades tradicionales, que mantienen durante siglos las proporciones originales de sus embarcaciones. Dicho esto, compárense la forma y las dimensiones de un curragh de dos remeros con las de la barca de piedra de San Juan de la Misarela (Figs. 3 y 2). Que cada uno saque sus propias conclusiones. Personalmente, creo que esta barca de piedra fue labrada por los monjes en una fecha imposible de precisar, muy probablemente con algún fin evangelizador. Ahora bien, ¿qué monjes? ¿bretones, irlandeses? De lo único que estoy seguro es de que sus formas no se corresponden con las de ninguna de las embarcaciones que sabemos que se utilizaron en la Península Ibérica en el pasado.

William Wey en su diario de viaje escrito en el año 1456, relata su pe-

"CUADERNOS DE ESTUDIOS GALLEGOS", Tomo XXXIX, Fascículo 104, Santiago 1991. 
regrinaje a Compostela y recoge una canción enigmática que pudo haber influido mucho en el ánimo evangelizador de los antiguos monjes navegantes. Cuenta que los discípulos del Apóstol que iban en la barca de piedra con el cuerpo de su maestro, venían cantando:

"Tu camino está en el mar y tu sendero sobre las grandes olas"

(In mare viae tuae et semitae tuae in aquis multis) (Wey, W., 1857, 156. Vázquez de Parga, L., 1981, 130).

Ojalá que el espíritu soñador de esos nautas tan singulares nos ayude a encontrar la solución de este enigma. 


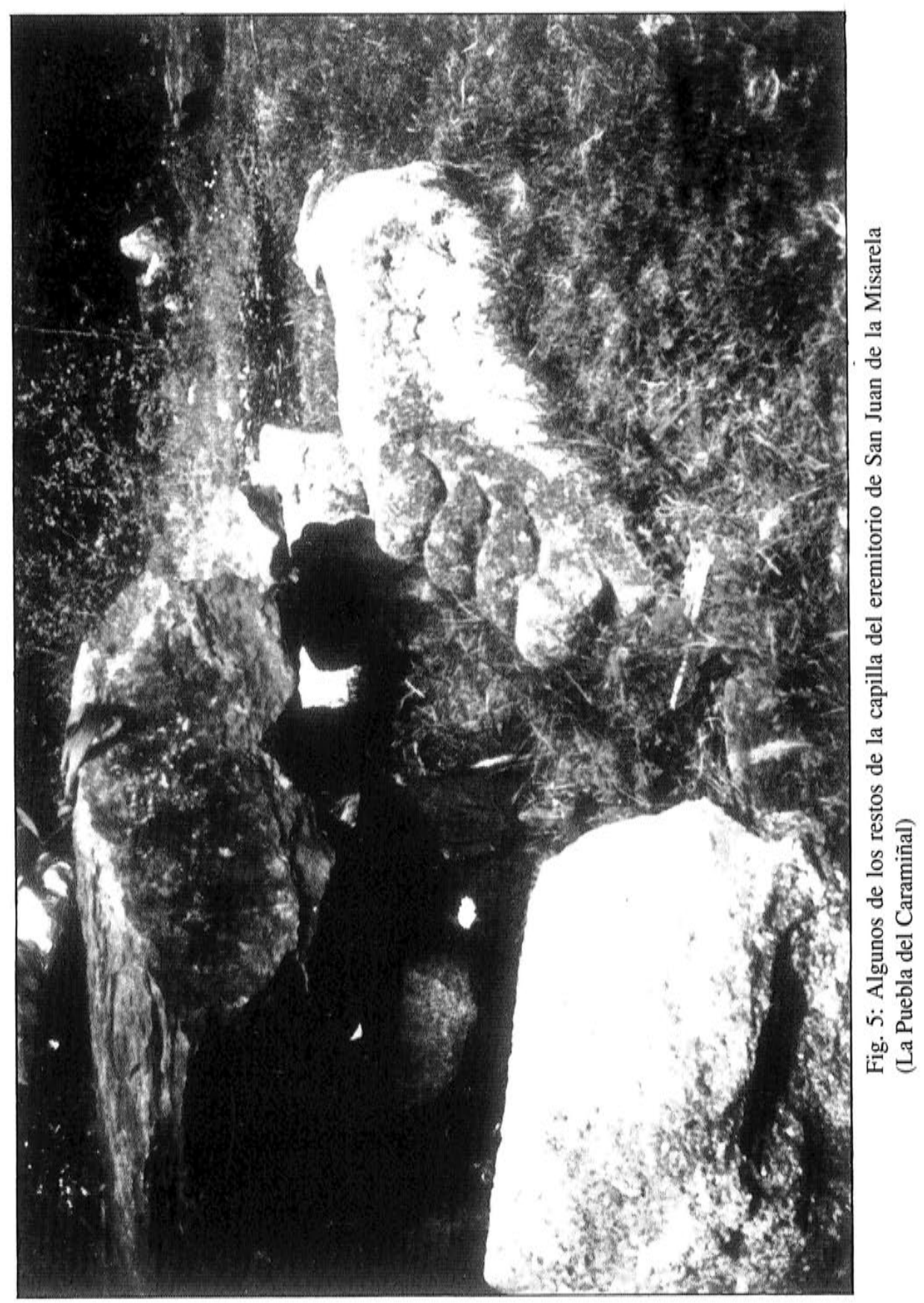

(c) Consejo Superior de Investigaciones Científicas 


\section{BIBLIOGRAFÍA}

ALONSO ROMERO, F., 1976. Relaciones atlánticas prehistóricas entre Galicia y las Islas Británicas y medios de navegación (Castrelos. Vigo).

ALONSO ROMERO, F., 1983. La leyenda de la Reina Lupa en los montes del Pindo. (Cuadernos de Estudios Gallegos, vol. 99, pp. 227267).

BAUMGARTEN, R., 1984. The Geographical Orientation of Ireland in Isidore and Orosius. (Peritia. Journal of the Medieval Academy or Ireland, vol. 3, pp. 189-203).

BERNIER, G., 1983. As igrexas bretonas en Galicia. (Tesis doctoral. Trad. de Pilar Ozores. Boletín do Museo Provincial de Lugo, vol. I, pp. 67-74).

CARRO OTERO, J. y MASA VÁZQUEZ, Maa A., 1981. Santuarios impetratorios de la fecundidad humana. (I Coloquio Galaico-Minhoto. Ponte de Lima, vol. II, pp. 233-247).

CÉSAR, Guerra de las Galias.

CHAMOSO LAMAS, M., 1967. Las primitivas Diócesis de Britonia y de San Martín de Mondoñedo a la luz de recientes descubrimientos. (Bracara Augusta, vol. 21, pp. 356-359).

CHAMOSO LAMAS, 1975. Avance informativo sobre las excavaciones arqueológicas realizadas en Bretoña (Lugo) durante las campañas de 1970 y 1971 . ( Noticiario Arqueológico Hispánico. Prehistoria 4. Madrid, pp. 268-271).

DAVID, P., 1947. Études historiques sur la Galice et le Portugal du VIe au XIIIe siècle (Paris).

DÍAZ y DÍAZ, M., 1972. Liber de Ordine Creaturarum. Un anónimo irlandés del siglo VII (Santiago de Compostela).

EROLO, 1984. En El Ideal Gallego, 17-IV, p. 31.

ETTLINGER, E., 1960. Les conditions naturelles des légendes celtiques. (Ogan, vol. XII).

GARCÍA y GARCÍA, A., 1986. Ecclesia Britoniensis. (Estudios Mindonienses, vol. 2. Diócesis de Mondoñedo, pp. 121-134).

GONZÁLEZ BLANCO, A., 1981. El cristianismo en el municipio de Calahorra del 380 al 410. (Memorias de Historia Antigua, vol. V. Universidad de Oviedo).

GWENC'HLAN LE SCOUEZEC, 1979. Guide de la Bretagne Mystérieuse (Paris).

GWYNN JONES, T., 1979. Weslh Folklore and Folk-Customs. (S.S. Brewer. London).

HILLGARTH, J.N., 1984. Ireland and Spain in the Seventh Century. (Peritia. Journal of the Medieval Academy of Ireland, vol. 3, pp. 116).

HORNELL, J., 1938. The Curraghs of Ireland. Part III. (The Mariner's Mirror, vol. 24, pp. 5-39. Cambridge University Press). 
HUNT, R., 1969. Cornish Folklore. (Tor Mark Press. Truro).

I.G.B. The Illustrated Guide to Britain (AA Publications. London, 1974).

LAREDO VERDEJO, L., 1981. Galicia enteira. Rías Baixas do Norte. (Edicións Xerais de Galicia).

LOGAN, P., 1980. The Holy Wells of Ireland. (Colin Smythe. Gerrads Cross).

MACIÑEIRA PARDO DE LAMA, F., 1921. San Andrés de Teixido. (La Coruña).

MATTOSO, J., 1985. Portugal medieval. (Imprensa Nacional. Lousâ).

McGRAIL, S., 1987. Ancient Boats in N.W. Europe. (Longman. London).

ORLANDIS, J. y RAMOS LISSON, 1986. Historia de los concilios de la España romana y visigoda. (Universidad de Navarra. Pamplona).

ORTEGA, A., (Trad.) 1981. Obras completas de Aurelio Prudencio. (Biblioteca de Autores Cristianos. Madrid).

PROPP, V., 1981. Las raíces históricas del cuento. (Trad. de J. Martín Arancibia. Editorial Fundamentos. Madrid).

RIVADULLA PORTA, J.E., 1974. Notas históricas del Santuario de Nuestra Señora de la Barca (Muxía). (La Coruña).

ROSS, A., 1968. Pagan Celtic Britain. (Routledge \& Kegan Paul. Londres).

SÁNCHEZ ALBORNOZ, C., 1929. Fuentes para el estudio de las divisiones eclesiásticas visigodas. (Boletín de la Universidad de Santiago de Compostela, II, 4 (Historia), pp. 29-83).

SÁNCHEZ ALBORNOZ, 1981. Estudios sobre Galicia en la temprana Edad Media. (Fundación Pedro Barrié de la Maza. La Coruña).

SARMIENTO, M. Fr. Viaje a Galicia. 1745. (Edición y estudio de J.L. Pensado. Universidad de Salamanca, 1975).

SEBILLOT, P., 1983 (A). La Mer. (1를 edición: 1904. Imago. Paris).

SEBILLOT, P., 1983 (B). La terre et le monde souterrain. (1를 edición: 1904. Imago. Paris).

TORRES RODRÍGUEZ, C., 1985. Paulo Orosio, su vida y sus obras. (Fundación Barrié. La Coruña).

TOVAR, A., 1972. Un obispo con nombre británico y los orígenes de la diócesis de Mondoñedo. (Habis, vol. 3, pp. 155-158. Universidad de Sevilla).

USERO, R., 1972. El santuario de San Andrés de Teixido (Santiago).

VÁZQUEZ DE PARGA et al., 1981. Las peregrinaciones a Santiago de Compostela (Diputación Provincial. Oviedo).

VON SYDOW, C.W., 1965. Folktale Studies and Philology: Some Points of View. (En: The Study of Folklore. Alan Dunder (Ed.). Printice Hall. Londres).

WEY, W., 1857. The itineraries of William Wey. (Roxburghe Club. Londres). 